\title{
Evaluation of growth performance and slaughter traits of Aseel chicken grown with and without outdoor access
}

\section{Muhammad Shafique Rehman}

Livestock and Dairy Development, Poultry Research Institute, Rawalpindi-Pakistan

Muhammad Tahir Khan ( $D$ mtahirkhan@cuvas.edu.pk)

Cholistan University of Veterinary and Animal Sciences, Bahawalpur

Fazal Raziq

Department of Livestock and Dairy Development, KPK-Pakistan

\section{Erum Bughio}

Shaheed Benazir Bhutto University of Veterinary and Animal Sciences, Sakrand

\section{Saima Liaqat}

The Islamia University of Bahawalpur Pakistan

\section{Mushtaq Ahmad Gondal}

Cholistan University of Veterinary and Animal Sciences, Bahawalpur, Pakistan

\section{Mubasher Rauf}

CUVAS, Bahawalpur

Muhammad Mozam Jalees

CUVAS, Bahawalpur

\section{Zahid Farooq}

CUVAS, Bahawalpur

\section{Fozia Sarwar}

PRI, Rawalpindi, Pakistan

\section{Ayesha Azad}

PRI, Rawalpindi, Pakistan

\section{Muhammad Azhar}

CUVAS, Bahawalpur

\section{Tahreem Asad}

CUVAS, Bahawalpur

\section{Muhammad Arslan}

CUVAS, Bahawalpur

\section{Ghulam Abbas}

Ripha College Veterinary Sciences, Lahore

\section{Muhammad Shakir}


PRI, Rawalpindi, Pakistan

\section{Research Article}

Keywords: Aseel, growth performance, outdoor access, slaughter trait

Posted Date: February 10th, 2022

DOI: https://doi.org/10.21203/rs.3.rs-1179992/v1

License: (c) (1) This work is licensed under a Creative Commons Attribution 4.0 International License. Read Full License 


\section{Abstract}

A study was conducted to investigate the effects of free-range, part-time free range, and confinement rearing systems on growth performance and slaughter traits in Lakha, Mushki, Peshawari, and Sindhi Aseel for 10-week duration (7-16 week). In total, 216 Aseel cockerels (6-wk-old), 54 from each variety, were allotted to 12 experimental groups, in a $3 \times 4$ (rearing system $\times$ Aseel variety) factorial arrangement under a randomized complete block design, replicated 3 times with 6 birds in each. Final body weight, weight gain, folds of increase, and mortality parameters of growth performance and carcass yield, breast, thigh, drumstick, wing, liver, gizzard, and heart parameters of slaughter traits were evaluated. Data were analyzed by using 2-way ANOVA under factorial arrangement. The results indicated increased body weight gain, folds of increase, breast and drumstick in both confinement and part-time free range $(P<0.05)$, whereas enhanced body weight, dressing, thigh, liver, and gizzard only in confinement rearing system. Among the Aseel varieties, Sindhi showed enhanced final body weight, weight gain, thigh and drumstick yields, whereas breast and gizzard weights were found to be greater in Lakha and Sindhi. Carcass yield, however, remained higher in all varieties except Peshawari. In conclusion, indoor rearing system had positive effects on growth and carcass-related parameters. Among the varieties, Sindhi showed better growth and slaughter-related performance traits in alternative rearing systems and hence, can be used as slower growing meat chicken in the aforesaid systems of poultry production in developing countries for better livelihood.

\section{Introduction}

In recent days, alternative rearing systems are becoming attractive due to limited use of chemical additives, synthetic fertilizers and antibiotics (Castellini et al. 2008). Natural environment in free-range provides fresh vegetation and grasses to the birds (Glatz et al. 2005) and their droppings act as organic fertilizers, enhancing soil fertility yielding greater beans and crops (Hilimire et al. 2012). High quality forages like grasses, legumes and clover improve nutrient intake in birds (Mikulski et al. 2011). Birds in free range disperse in small groups, having complete freedom of expressing their natural behavior (Chen et al. 2013; Tong et al. 2014; Wang et al. 2015). Similarly, part-time free range rearing system improves behavioral activities as well as their performance of the birds (Barbosa-Filho et al. 2005). Variable pasture intake in free range system, however, may adversely affect weight gain and feed efficiency in chicken (Wang et al. 2009). Pasture management plays a crucial role in making free range healthier and more welfare friendly for the growing flocks (Sossidou et al. 2015).

In Pakistan, poultry farming has developed from a small scale family operation to a large scale, big business operation, resulting in closure of traditional open-sided poultry houses (Rehman 2017). This alarming situation urges poultry geneticists to explore such chicken breeds, which would be suitable for natural meat production in open environment, reviving the prestigious agro-based poultry culture and rehabilitation of livelihood in rural households (Rehman 2017; Desta 2021). Slow-growing chicken, being scavenging in nature, has an ability to survive on insufficient feed resources under traditional free range conditions (Fanatico et al. 2005a). Indigenous chicken is reared mainly by small poultry farmers within 
limited resources, generating income for their households (Magala et al. 2012). Aseel chicken is a wellknown indigenous breed of Indo-Pak subcontinent; popular for its better adaptability, hardiness, and low mortality in sub-tropical region like Pakistan (Khan et al. 2017).

Mainly 16 Aseel varieties are inhabitant to Pakistan (Khan, UAF: Personal Communication), out of which, Lakha is characterized by reddish-brown plumage with black or white mottling, Mushki has a black plumage with black pigmentation in beak and shanks, Peshawari has a wheaten-colored plumage (Babar et al. 2012), and Sindhi possesses a reddish-brown plumage with hard and short feathers (Rehman et al. 2017). On the basis of robustness, disease resistance, better adaptability to the inclement climatic conditions, and excellent meat producing qualities, Aseel may be used for meat production in alternative rearing systems and help in the revival of small-scale rural poultry farming in open-sided houses. A lot of work has been done in India using Aseel chicken in the farm as well as in field conditions, however, no specific work has, so for, been conducted to investigate the performance of Aseel chicken under freerange, part-time free range, and confinement rearing systems. The present study, therefore, was planned to evaluate the growth performance and slaughter traits in 4 varieties of Aseel chicken (Lakha, Mushki, Peshawari, and Sindhi) under free-range, part-time free range, and confinement rearing systems.

\section{Methodology}

\section{Experimental Station, Birds and Rearing Systems}

The present study was conducted at Indigenous Chicken Genetic Resource Centre (ICGRC), Department of Poultry Production, Ravi Campus (located at $31^{\circ} 10^{\prime}$ North and $73^{\circ} 51^{\prime}$ East longitudes) University of Veterinary and Animal Sciences (UVAS), Lahore, for 10 week duration (7-16 weeks). The summers are sweltering, humid and clear whereas the winters are short, cool and dry. Long-term average annual temperature at Pattoki varies from $28^{\circ} \mathrm{C}$ to $40^{\circ} \mathrm{C}$. Average annual relative humidity ranges between 40 and $75 \%$.

\section{Bird, s Husbandry}

In total, 216 Aseel cockerels, 54 from each variety were randomly assigned to 12 experimental groups, in a $3 \times 4$ (rearing system $\times$ Aseel variety) factorial arrangement under a randomized complete block design. Each experimental group was replicated 3 times with 6 birds in each replicate. All birds in each variety were weighed before the start of experiment and they were uniform in body weight. Experimental birds were maintained in an independent open-sided poultry house, measuring $6.1 \times 6.1 \mathrm{~m}\left(37.21 \mathrm{~m}^{2}\right)$ with East to West dimension, opening towards North in free range. The house was equipped with a 3-tiered growing cage, measuring $1.52 \times 4.57 \mathrm{~m}\left(20.84 \mathrm{~m}^{2}, 6.91 \mathrm{birds} / \mathrm{m}^{2}\right)$, with removable dropping trays and automatic nipple drinking system. Trough feeders were available for feeding of the birds. Free-range area (specified for free range and part-time free range; stocking density, $0.27 \mathrm{birds} / \mathrm{m}^{2}$ ) was surrounded by a $2.44 \mathrm{~m}$ high enclosure to avoid the entry of predators. Seasonal legumes (cereals, beans, cowpeas, lentils, and 
grasses) and non-legumes were cultivated in free range. Replication in free range was done with the help of fish-net and fresh water in each replicate was available through nipple drinking system.

Birds under confinement rearing system remained $24 \mathrm{~h}$ in cages with 100 allowance $(0800 \mathrm{~h})$ of cornsoybean based broiler grower ration (Table 1). The ration used was iso-nitrogenous and iso-caloric (20.00 CP, $3,050 \mathrm{kcal} / \mathrm{kg} \mathrm{ME}$ ). The birds under part-time free range system had access to free range from 0800 to $1200 \mathrm{~h}$. Subsequently, they were maintained in cages from 1200 to $0800 \mathrm{~h}$ and offered 50 of feed allowance at $1700 \mathrm{~h}$. However, birds under the free range system had free access to free range area from 0800 to $1600 \mathrm{~h}$. Thereafter, they were shifted to the house and maintained on floor from 1600 to $0800 \mathrm{~h}$ (stocking density, 2.38 birds $/ \mathrm{m}^{2}$ ), with rice husk as bedding material $(15 \mathrm{~cm})$ and offered 25 feed allowance $(1700 \mathrm{~h})$. Natural light and similar prophylaxis and hygienic measures were adopted in all rearing systems. The experimental birds were vaccinated against Newcastle disease (ND), infectious bronchitis (IB), and infectious bursal disease (IBD), following the recommendations of vaccine manufacturing company under the supervision of a qualified veterinarian. Throughout the trial, temperature and $\mathrm{RH}$ remained in the range of 13 to 30 and 52 to 67 , respectively. Such variations in daily temperature and humidity (\%) were noted using a wet and dry bulb hygrometer (Mason's type, Zeal, England) and later an average of the temperature and humidity were derived on weekly basis as shown in Fig. 1.

\section{Data Collection}

Initial and final body weights were recorded by using electronic balance (accuracy of $0.01 \mathrm{~g}$ ) (WANT ${ }^{\circledR}$ Wt$\mathrm{G})$ to calculate the body weight gain and folds of increase. Daily mortality, if any, was recorded to calculate the percentage of mortality. At the end of $16^{\text {th }}$ week, a total of 72 birds, 2 from each replicate with average body weight, were picked and tagged according to variety and rearing system. They were kept off-feed for 4 hours before slaughtering. Birds were weighed and slaughtered manually according to the Halal (Farouk et al. 2014) method of slaughtering, allowed to bleed for 3-4 minutes, and feather plucking was done after scalding the carcass at 50-60 for 1-1.5 minutes. Carcass yield was taken as weight of hot eviscerated carcass without skin after removing shanks, head, feathers, and abdominal fat (except the lungs and kidneys) in relation to the live weight multiplied by 100 (CFIA 1999). Percentages of breast, thigh, drumstick and wing were calculated as their individual weight relative to the dressed weight multiplied by 100 , whereas liver, gizzard, and heart percentages were calculated as in relation to the live weight multiplied by 100 .

\section{Statistical Analysis}

The data were tested for homogeneity of variance across the experimental groups, verified for the normality of variance and subjected to the 2-way ANOVA under factorial arrangement by using GLM procedure of SAS version 9.1 (SAS Institute Inc., 2002-03). Variety and rearing system were considered as main effects and their interaction was also tested. Means among treatments were compared through Duncan's Multiple Range test (Duncan 1955) (SAS Institute Inc., 2002-03) at 5 \% probability level. 
The statistical model used was:

$Y_{i j k}=\mu+R_{i}+V_{j}+(R \times V)_{i j}+\varepsilon_{i j k}$

Where, $Y_{i j k}=$ Observed dependent variable; $\mu=$ Overall mean; $\mathrm{R}_{\mathrm{i}}=$ Effect of rearing system; $\mathrm{V}_{\mathrm{j}}=$ Effect of Aseel variety; $(\mathrm{R} \times \mathrm{V})_{\mathrm{ij}}=$ Interaction in rearing system \& Aseel variety; and $\varepsilon_{i j k}=$ Residual error.

\section{Results}

\section{Growth Performance}

In the present study, final body weight was significantly affected $(P<0.05)$ by the rearing systems and the Aseel varieties. Highest $(P<0.05)$ body weight was observed in birds reared in confinement (Table 2$)$ followed by those in part-time and free range. Among the varieties, Sindhi birds showed the highest $(P<0.05)$ final body weight followed by those of Lakha, Mushki and then Peshawari. Birds reared in confinement and part-time free range exhibited increased $(P<0.05)$ weight gain as compared with those in free range. Among the varieties, birds of Sindhi showed the highest $(P<0.05)$ weight gain followed by those of Lakha, Mushki and then Peshawari. Folds of increase were found to be greater in confinement and part-time free range than free range whereas Aseel varieties independently and in interaction with rearing systems did not affect $(P=0.584)$ folds of increase. Mortality was found to be lower $(P<0.05)$ in birds reared in confinement followed by those in part-time free range and free range whereas varieties independently and in interaction with the rearing systems did not influence $(P>0.05)$ mortality percentage.

\section{Slaughter Traits}

In the current study, carcass yield increased $(P<0.05)$ in birds reared indoor (Table 3$)$ followed by those in part-time free range and free range. Among the Aseel varieties, birds of Sindhi, Mushki, and Lakha showed higher $(P<0.05)$ carcass yield than those of the Peshawari (Table 4). Breast yield increased $(P<0.05)$ in free range than part-time free range and confinement rearing systems. Among the varieties, birds of Lakha and Sindhi showed increased $(P<0.05)$ breast yield than those of the Peshawari. Thigh yield was found to be greater $(P<0.05)$ in birds reared indoor followed by those in part-time free range and free range. Among the varieties, birds of Sindhi showed higher $(P<0.05)$ value of thigh yield than those of the Mushki and Peshawari. Birds reared indoor showed higher $(P<0.05)$ drumstick yield compared to those under part-time free range and free range systems. Among the varieties, Sindhi showed increased $(P<0.05)$ value of drumstick yield than the Peshawari.

In the present study, all treatments including rearing systems $(P=0.189)$, Aseel varieties $(P=0.098)$, and their interaction $(P=0.216)$ showed did not influence wing percentage whereas value of liver percentage was found to be highest $(P<0.05)$ in birds reared in confinement followed by those in part-time free range and free range. Among the varieties, Lakha demonstrated increased $(P<0.05)$ liver weight compared with the Peshawari and Mushki. Birds under the confinement rearing system showed the highest $(P<0.05)$ value of gizzard weight followed by those under part-time free range and free range. Among the varieties, 
birds of Lakha and Sindhi exhibited higher $(P<0.05)$ gizzard weight than those of the Mushki and Peshawari. Rearing systems as well as Aseel varieties did not influence heart percentage $(P=0.998$; $P=0.408)$.

\section{Discussion}

Free-range rearing can directly and indirectly affect health, welfare, productivity and quality of local chickens in terms of their growth performance and carcass yield (Tong et al. 2014; Stadig et al. 2016). Consumer interest for poultry products derived from free-range systems is on rising trend (Chen et al. 2013; Tong et al. 2014; Wang et al. 2015).

\section{Growth Performance}

Growth performance indicators are often used to assess poultry production (Zhang et al. 2018b). Previous studies have indicated that poultry growth performance indicators are affected by rearing systems (Wang et al. 2009; Liu et al. 2011; Wang et al. 2015).

In the present study, birds reared indoor achieved the highest $(P<0.05)$ body weight (Table 2$)$ followed those in part-time free range and free range. This can be attributed to the availability of balanced diet and absence of activities like walking, running and jumping in confinement. In line with these results, Pavlovski et al. (2009) reported that the chickens reared indoor were significantly heavier than free-range chickens. According to Ward et al. (2001), the 40-days old broiler-reared Ross pullets achieved considerably higher body weight compared to free-range birds at the same age. Ponte et al. (2008) and Dou et al. (2009), likewise, observed increased body weight in birds reared indoor, indicating that intensive system of poultry production is better in term of body growth of the birds (Milosevic et al. 2005; Santos et al. 2005; Skomorucha et al. 2008; Pavlovski et al. 2009). Poltowicz \& Doktor (2011) also reported higher body weight in indoor reared birds than those of free-range. Wang et al. (2009) reported that slow-growing Gushi chickens reared indoors to day 112 of age achieved significantly higher body weight compared to free-range chickens. Similarly, Ahmad et al. (2019) concluded that birds under intensive and semiintensive systems were significant heavier at slaughter than free range birds. In the present study, lower body weight of birds in free range system can be attributed to greater energy expenditure by the birds. Ricke et al. (2012) also indicated that great physical activity and the large energy expenditure associated with the thermoregulation of organic birds can influence their production properties. Similarly, A study by Jin et al. (2019) reported that body weight of birds decreased significantly $(P<0.05)$ in the first 2 week after birds were assigned to free-range treatment compared with those in the conventional treatment. Among the varieties, Sindhi showed the highest $(\mathrm{P}<0.05)$ final body weight followed by Lakha, Mushki and then Peshawari. According to Mikulski et al. (2011), genetic has a major share in body weight (Batkowska et al. 2015); therefore, difference in final body weight among the varieties may be attributed to the differences in their genetic make-up.

Confinement and part-time free range demonstrated increased $(P<0.05)$ weight gain compared with free range. As mentioned above, birds reared indoor achieved greater $(P<0.05)$ body weight $($ Table 2$)$ that 
might have resulted in increased weight gain of the birds. Similar to these findings, Castellini et al. (2002a) and Dou et al. (2009) observed increased weight gain in indoor rearing system than freerange, indicating that indoor system of poultry production is better than free-range in term of weight gain (Wang et al. 2009). More locomotor activity and less rest could be the reasons for poorer growth rate of birds in free-range. Jin et al. (2019) reported that average daily gain decreased significantly $(P<0.05)$ for chickens assigned to free-range treatment from 56 to 70 D of age. Similarly, Li et al. (2017) reported that the body weight gain of free-range broilers were lower than in those kept in cage and indoor-range systems. The negative effect of the organic rearing system of chickens on body weight gain was also reported by Castellini et al. (2002b) for Ross cockerels aged 56 and 81 days. Among the varieties, Sindhi showed the highest $(P<0.05)$ weight gain followed by Lakha, Mushki and then Peshawari. Patterns of growth depend largely on inherent ability of the birds for growth (Santos et al. 2005); hence, increased gain in Sindhi may be attributed to its better genetic potential.

In the present study, higher folds of increase was observed in confinement and part-time free range. This may be attributed to the balanced diet and better management of the birds in confinement. Similarly, Dou et al. (2009) reported higher folds of increase in birds reared indoor than free range, supporting the argument that indoor rearing system regarding growth is better than the other rearing systems (Magala et al. 2012). Aseel varieties independently and in interaction with the rearing systems did not influence $(P=0.584)$ folds of increase. Mortality percentage was found to be lower in birds reared indoor followed by part-time free range and free range. Balanced diet, better management and relatively improved biosecurity in confinement rearing system are assumed to cause reduction in mortality. Similar to these findings, reduced mortality in indoor system of poultry production compared to free-range has previously been reported (Farooq et al. 2002; Poltovics \& Doktor 2011). According to Baeza et al. (2001), free-range access caused increased mortality. Varieties independently and in interaction with the rearing systems indicated no effect $(P>0.05)$ on mortality.

\section{Slaughter Traits}

Carcass yield is an important trait for poultry production that may affect both consumers' purchase intention and poultry production profits (Tong et al. 2015; Zhang et al. 2018b). In the present study, carcass yield increased $(P<0.05)$ in confinement rearing system (Table 3 ) followed by part-time free range and free range. As stated above, birds assigned to confinement rearing system achieved larger body weight than those in the part-time free range and free range, which might have contributed to carcass yield. Similarly, Skomorucha et al. (2008) reported increased carcass yield in an indoor rearing system than outdoor. Castellini et al. (2002a) and Ahmad et al. (2019), likewise, reported a positive effect of outdoor access on the carcass yield. Among the varieties, Sindhi, Mushki, and Lakha showed greater $(P<0.05)$ carcass yield than Peshawari (Table 4). Literature has shown that carcass yield depends largely on live weight of the birds (Moujahed \& Haddad, 2013). Hence, increased carcass yield in Sindhi, Mushki, and Lakha may be attributed to their higher body weight (Table 2). Fanatico et al. (2005b) also indicated direct association of dressing percentage with final body weight of the birds. 
In the present study, breast yield increased $(P<0.05)$ in birds reared outdoor than indoor. It is quite possible that more physical exercise and locomotor activity in free range might have promoted breast muscle accretion. Similarly, Sales (2014) and Tong et al. (2015) reported increased breast yield in birds reared outdoor than indoor, indicating that free range system of poultry production is better in term of breast yield (Castellini et al. 2002a; Ahmad et al. 2019). Jin et al. (2019), likewise, reported that breast yield of the birds increased linearly with increasing free-range days $(P<0.05)$. Castellini et al. $(2002 b)$, likewise, observed that birds having free-range access were characterized by a higher percentage of breast muscles in the carcass. Skomorucha et al. (2008), however, reported that the birds reared indoors achieved higher breast muscle yield compared to the birds grown with outdoor access. Similarly, no significant effect $(P>0.05)$ of free range on the breast yield has also been reported in literature (Fanatico et al., 2005; Wang et al. 2009). Among the Aseel varieties, birds of Lakha and Sindhi showed greater $(P<0.05)$ breast yield than those of the Peshawari. This may be attributed to the high breast weight and carcass weight ratio (BW/CW) in Lakha and higher final body weight and weight gain in Sindhi. There are reports that different strains (Mikulski et al. 2011) or breeds (Musa et al. 2006) behave differently with respect to breast weight.

Increased $(P<0.05)$ thigh yield was observed in confinement rearing system followed by part-time free range and free range. Birds assigned to confinement rearing system had larger body weight and weight gain than those under part-time free range and free range, which might have contributed to thigh yield. In line with these results, Ahmad et al. (2019) observed that birds reared indoor had higher thigh yield than semi-intensive and free-range birds. Poltovics \& Doktor (2011), likewise, reported greater thigh weight in indoor rearing system than the free-range, concluding that thigh yield varies due to rearing systems (Castellini et al. 2002a; Magala et al. 2012). The positive effect of free-range on thigh yield was also reported by Castellini et al. (2002b). Among the varieties, Sindhi showed higher $(P<0.05)$ value of thigh yield than Mushki and Peshawari. Higher value of thigh yield in Sindhi may be a result of higher body weight and weight gain (Table 2) of the Sindhi birds. According to reports, thigh yield has a close association with genotype of the bird (Musa et al. 2006; Mikulski et al. 2011).

Birds reared indoor showed higher $(\mathrm{P}<0.05)$ drumstick yield compared with part-time free range and free range. This may be related to less exercise and minimum activity of birds in confinement rearing system. Similar to these findings, Ahmad et al. (2019) found that birds reared indoor achieved higher drumstick weight compared to free-range and part-time free-range systems. Inci et al. (2016), likewise, observed variations in drumstick weight of quails under different rearing systems. Among the varieties, Sindhi showed increased drumstick yield than Peshawari. This may be attributed to the higher body weight of Sindhi (Table 2). Effect of different genotypes (Musa et al. 2006) and breeds (Ojedapo et al. 2008; Mikulski et al. 2011) on drumstick weight has already been reported in literature. Rearing systems $(P=0.189)$, Aseel varieties $(P=0.098)$, and their interaction $(P=0.216)$ did not influence wing percentage. According to reports, genotype has little or no effect on wing percentage (Santos et al. 2005). Hence, it can be concluded that wing percentage might not be genotype dependent. Similar reports were presented by Faria et al. (2010) who compared different strains of birds, indicating that different breeds (Choo et al. 2014; Hrncar et al. 2015) or genotypes (Batkowska et al. 2015) had no effect on wing percentage. No 
significant effect of different rearing systems on wing weight has also been reported in literature (Tong et al. 2014). Like a study by Wang et al. (2009) showed no significant differences in the percentage of wing muscles between chickens reared in free-range and conventional systems. However, Ahmad et al. (2019) found higher wings weight in intensive birds compared to semi-intensive and free-range birds.

Value of the liver percentage was found to be highest $(P<0.05)$ in birds reared indoor followed by those in part-time free range and free range, which can be attributed to the fact that lack of exercise (with fewer nutrients being expended for energy) and high energy diet stimulated hepatic lipogenesis. In line with these results, Bughio et al. (2021) reported that intensively reared birds had higher liver weight compared to free-range birds. Similarly, Hanyani $(2012)$ and Zhao et al. $(2012,2015)$ reported heavier livers in chickens raised in cages than those reared on the floor. Hrncar et al. (2014), likewise, reported higher liver weights in ducks reared in cages than those of deep litter floor systems. Ahmad et al. (2019), however, found that liver weight increased in semi-intensive birds as compared to free-range and intensive systems. Similarly, Adedeji et al. (2014) and Abdullah and Buchtova (2016) observed that the livers of organically raised chicken broilers were heavier than those of conventionally bred birds. Among the varieties, Lakha demonstrated increased liver percentage $(P<0.05)$ than Peshawari and Mushki. Reasons for increased liver weight in Lakha compared to Peshawari and Mushki could not be readily ascertained. According to Musa et al. (2006), liver weight varies from strain to strain (Santos et al. 2005), variety to variety (Jatoi et al. 2015) and breed to breed (Ojedapo et al. 2008).

In the present study, value of gizzard weight was observed to be highest $(P<0.05)$ in birds reared indoor followed by those in part-time free range and free range. Similarly, Santos et al. (2005) also observed a significant effect of rearing system on gizzard weight (Ahmad et al. 2019). Inci et al. (2016), however, reported that there is no effect of rearing system on gizzard weight. Among the varieties, Lakha and Sindhi exhibited $(P<0.05)$ higher gizzard weight than Mushki and Peshawari. Musa et al. $(2006)$ and Ojedapo et al. (2008) also observed significant breed or genotype effect on gizzard weight. Jatoi et al. (2015), however, presented the fact other way round, reporting no significant effect of genotype on gizzard weight, which was further corroborated by the findings of Chen et al. (2013) and Batkowska et al. (2015). Rearing systems $(P=0.998)$ as well as Aseel varieties $(P=0.408)$ did not influence heart weight. Similarly, it was reported that different Aseel varieties (Jatoi et al., 2015) as well as genetic groups of poultry (Chen et al. 2013; Batkowska et al. 2015) showed no effect on heart weight. As mentioned above, rearing systems did not influence heart weight. These findings are in agreement with those of Inci et al. (2016) whose study showed no significant effect of rearing systems on heart weight.

Based on the current findings, it can be concluded that confinement rearing system had positive effects on growth and carcass-related parameters of indigenous Aseel chicken. Among the Aseel varieties, Sindhi showed better growth potential, hence could be used as slower growing meat-type chicken in alternative rearing system, reviving agro-based rural poultry activity, bringing small poultry farmers into business.

\section{Declarations}


Acknowledgements

The authors gratefully acknowledge the Department of Poultry Production, University of Veterinary and Animal Sciences, Lahore for supporting the trial.

\section{Funding}

Not applicable

\section{Competing Interests}

No potential conflict of interest was found by the authors.

\section{Ethics Approval}

The study was approved by the Ethical Review Committee of the University of Veterinary and Animal Sciences, Lahore, Pakistan.

\section{Consent to Participate}

Informed consent was obtained from all individual participants included in the study.

\section{Consent for Publication}

The authors have consented to the submission of the manuscript to the journal.

\section{Availability of Data and Material}

The datasets generated during and/or analyzed during the current study are available from the corresponding author on reasonable request.

\section{Code Availability}

Not applicable

\section{Authors' Contribution}

All authors contributed to the study conception, design, material preparation, data collection, analysis and drafting of the manuscript.

\section{References}

1. Abdullah, F.A.A. and Buchtova, H., 2017. Quantity and quality properties of breast and thigh of chicken broilers from organic and conventional production systems. Journal of Food Safety and Food Quality-Archiv fur Lebensmittelhygiene, 68, 56-61. 
2. Adedeji, O. S., Amao, S.R., Oguntunde, M.M. and Dada, I.D., 2014. Evaluation of general performance and carcass qualities of organically raised broiler chickens from day old to 12 weeks of age. International Journal of Agriculture Innovations and Research, 2, 466-471.

3. Ahmad, S., Mahmud, A., Hussain, J. and Javed, K., 2019. Morphological and carcass traits of three chicken genotypes under free-range, semiintensive and intensive housing systems. Turkish Journal of Veterinary and Animal Sciences, 43, 342-352.

4. Babar, M.E., Nadeem, A., Hussain, T., Wajid, A., Shah, S.A., Iqbal, A., Sarfraz, Z. and Akram, M., 2012. Microsatellite marker based genetic diversity among four varieties of Pakistani Aseel chicken. Pakistan Veterinary Journal, 32, 237-241.

5. Baeza, E., Lessire, M., Berri, C. and Juin, H., 2001. Compared carcass and meat characteristics of label and standard guinea fowl. 15. European Symposium on the Quality of Poultry Meat, Kusadasi, Turkey, 73-78.

6. Barbosa-Filho, J.A.D., Silva, M.A.N, Silva, I.J.O., Coelho, A.A.D. and Savino, V.J.M., 2005. Behavior and performance of broiler strains reared under semi-intensive system with shaded areas. Brazilian Journal of Poultry Science, 7, 209-213.

7. Batkowska, J., Brodacki, A., Zieba, G., Horbanczuk, J.O. and Lukaszewicz, M., 2015. Growth performance, Carcass traits and physical properties of chicken meat as affected by genotype and production system. Archives Animal Breeding, 58, 325-333.

8. Bughio, E., Hussain, J., Mahmud, A. and Khalique, A., 2021. Effects of production system and feeding regimen on carcass and meat quality traits of Naked Neck chicken. South African Journal of Animal Science, 51, 250-261.

9. Castellini, C., Mugnai, C. and Bosco, D.A., 2002a. Effect of organic production system on broiler carcass and meat quality. Meat Science, 60, 219-225.

10. Castellini, C., Mugnai, C. and Bosco, A.D., 2002b. Meat quality of three chicken genotypes reared according to the organic system. Italian Journal of Food Science, 14, 411-412.

11. Castellini, C., Berri, C., Bihan-Duval, L.E. and Martino, G., 2008. Qualitative attributes and consumer perception of organic and free range poultry meat. World's Poultry Science Journal, 64, 500-512.

12. CFIA. Meat Cuts Manual. Canadian Food Inspection Agency 1999; Ottawa, ON, Canada.

13. Chen, X., Jiang, W., Tan, H.Z., Xu, G.F., Zhang, X.B., Wei, S. and Wang, X.Q., 2013. Effects of outdoor access on growth performance, carcass composition, and meat characteristics of broiler chickens. Poultry Science, 92, 435-443.

14. Choo, Y.K., Kwon, H.J., Oh, S.T., Um, J.S., Kim, B.G., Kang, C.W., Lee, S.K. and An, B.K., 2014. Comparison of growth performance, carcass characteristics and meat quality of Korean local chickens and silky fowl. Asian-Australasian Journal of Animal Sciences, 27, 398-405.

15. Desta, T.T., 2021. Indigenous village chicken production: a tool for poverty alleviation, the empowerment of women and rural development. Tropical Animal Health and Production, 53, 1-16.

16. Dou, T.C., Shi, S.R., Sun, H.J. and Wang, K.H., 2009. Growth rate, carcass traits and meat quality of slow-growing chicken grown according to three raising systems. Animal Science Papers and Reports, 
27, 361-369.

17. Duncan, D.B., 1955. Multiple ranges and multiple F tests. Biometrics, 11, 1-4.

18. Fanatico, A., Pillai, P., Cavitt, L., Owens, C. and Emmert, J., 2005a. Evaluation of slower-growing broiler genotypes grown with and without outdoor access: Growth performance and carcass yield. Poultry Science, 84, 1321-1327.

19. Fanatico, A.C., Cavitt, L., Pillai, P., Emmert, J. and Owens, C., 2005b. Evaluation of slower-growing broiler genotypes grown with and without outdoor access: Meat quality. Poultry Science, 84, 17851790.

20. Faria, P.B., Bressan, M.C., de Souza, X.R., Rossato, L.V., Botega, L.M.G. and da Gama, L.T., 2010. Carcass and parts yield of broilers reared under a semi-extensive system. Brazilian Journal of Poultry Science, 12, 153-159.

21. Farooq, M., Gul, N., Chand, N., Durrani, F., Khurshid, A., Ahmed, J. and Asghar, A., 2002. Production performance of backyard chicken under the care of women in Charsadda, Pakistan. Livestock Research for Rural Development, 14, 27-34.

22. Farouk, M.M., Al-Mazeedi, H.M., Sabow, A.B., Bekhit, A.E.D., Adeyemi, K.D., Sazili, A.Q. and Ghani, A., 2014. Halal and kosher slaughter methods and meat quality: A review. Meat Science, 98, 505-519.

23. Glatz, P.C., Ru, Y.J., Miao, Z.H., Wyatt, S.K. and Rodda, B.J., 2005. Integrating poultry into a crop and pasture farming system. International Journal of Poultry Science, 4, 187-191.

24. Hanyani, C.T., 2012. Effect of full and semi-scavenging rearing systems on crop contents and the quality of meat from village chickens during the spring season of eastern cape, South Africa. MSc. thesis, Department of Livestock and Pasture Science, Faculty of Science and Agriculture, University of Fort Hare, South Africa.

25. Hilimire, K., Gliessman, S.R. and Muramoto, J., 2012. Soil fertility and crop growth under poultry/crop integration. Renewable Agriculture and Food Systems, 28, 173-182.

26. Hrncar, C., Weis, J., Petricova, L. and Bujko, J., 2014. Effect of housing system, slaughter age and sex on slaughter and carcass parameters of broiler ducks. Scientific Papers Animal Science and Biotechnologies, 47, 254-257.

27. Hrncar, C., Gasparovic, M., Gàlik, B. and Bujko, J., 2015. Study of carcass parameters of Brahma, Cochin and Orpington chicken breeds. Scientific Papers Animal Science and Biotechnologies, 48, 142-145.

28. Inci, H., Ozdemir, G., Sogut, B., Sengul, A.Y., Sengul, T. and Taysi, M.R., 2016. Comparison of growth performance and carcass traits of Japanese quails reared in conventional, pasture, and organic conditions. Revista Brasileira de Zootecnia, 45, 8-15.

29. Jatoi, A.S., Iqbal, M., Sahota, A.W., Akram, M., Javed, K., Mehmood, S., Hussain, J. and Ishaq, H.M., 2015. Carcass characteristics and organ development in four different varieties of native Aseel chicken of Pakistan. Pakistan Journal of Science, 67, 127-132.

30. Jin, S., Yang, L., Zang, H., Xu, Y., Chen, X., Chen, X., Liu, P. and Geng, Z., 2019. Influence of free-range days on growth performance, carcass traits, meat quality, lymphoid organ indices, and blood 
biochemistry of Wannan Yellow chickens. Poultry Science, 98, 6602-6610.

31. Khan, M.T., Mahmud, A., Zahoor, I. and Javed, K., 2017. Organic and inorganic selenium in Aseel chicken diets: Effect on hatching traits. Poultry Science, 96, 1466-1472.

32. Li, Y., Luo, C., Wang, J. and Guo, F., 2017. Effects of different raising systems on growth performance, carcass, and meat quality of medium-growing chickens. Journal of Applied Animal Research, 45, 326-330.

33. Liu, B.Y., Wang, Z.Y., Yang, H.M., Wang, J.M., Xu, D., Zhang, R. and Wang, Q., 2011. Influence of rearing system on growth performance, carcass traits, and meat quality of Yangzhou geese. Poultry Science, 90, 653-959.

34. Magala, H., Kugonza, D.R., Kwizera, H. and Kyarisiima, C.C., 2012. Influence of management system on growth and carcass characteristics of Ugandan local chickens. Journal of Animal Science Advances, 2, 558-567.

35. Mikulski, D., Celej, J., Jankowski, J., Majewska, T. and Mikulska, M., 2011. Growth performance, carcass traits and meat quality of slower-growing and fast-growing chickens raised with and without outdoor access. Asian-Australasian Journal of Animal Sciences, 24, 1407-1416.

36. Milosevic, N., Peric, L., Strugar, V., Zikic, D. and Pavlovski, Z., 2005. Rearing of fattening chickens on free range and extensively in chicken coop. Biotechnology in Animal Husbandry, 21, 217-221.

37. Moujahed, A.R. and Haddad, B., 2013. Performance, livability, carcass yield and meat quality of Tunisian local poultry and fast-growing genotype (Arbor Acres) fed standard diet and raised outdoor access. Journal of Animal Production Advance, 3, 75-85.

38. Musa, H.H., Chen, G.H., Cheng, J.H., Li, B.C. and Mekki, D.M., 2006. Study on carcass characteristics of chicken breeds raised under the intensive condition. International Journal of Poultry Science, 5 , 530-533.

39. Ojedapo, L.O., Akinokun, O., Adedeji, T.A., Olayeni, T.B., Ameen, S.A. and Amao, S.R., 2008. Effect of strain and sex on carcass characteristics of three commercial broilers reared on deep litter system in the Derived Savannah area of Nigeria. World Journal of Agricultural Sciences, 4, 487-491.

40. Pavlovski, Z., Skrabic, Z., Lukic, M., Petricevic, V.L. and Trenkovski, S., 2009. The effect of genotype and housing system on production results of fattening chickens. Biotechnology in Animal Husbandry, 25, 221-229.

41. Poltowicz, K. and Doktor, J., 2011. Effect of free-range raising on performance, carcass attributes and meat quality of broiler chickens. Animal Science Papers \& Reports, 29, 139-149.

42. Ponte, P.I.P., Rosado, C.M.C., Crespo, J.P., Crespo, D.G., Mourao, J.L., Chaveiro-Soarres, M.A., Bras, J.L.A., Mendes, I., Gama, L.T., Prates, J.A.M., Ferreira, L.M.A. and Fontes, C.M.G.A., 2008. Pasture intake improves performance and meat sensory attributes of free-range broilers. Poultry Science, 87, 71-79.

43. Rehman, M.S., 2017. Welfare, growth, carcass and reproductive traits in indigenous chicken Aseel under free range, semi-intensive and confinement rearing systems. PhD Dessertation. UVAS, Lahore, Pakistan. 
44. Rehman, M.S., Mahmud, A., Mehmood, S., Pasha, T.N., Hussain, J. and Khan, M.T., 2017. Blood biochemistry and immune response in Aseel chicken under free range, semi-intensive and confinement rearing systems. Poultry Science, 96, 226-233.

45. Ricke, S.C., Van, Loo, E.J., Johnson, M.G. and O'Bryan, C.A., 2012. Organic meat production and processing. $1^{\text {st }}$ Ed. Wiley Scientific/IFT, New York, NY, 247-248.

46. Sales, J., 2014. Effects of access to pasture on performance, carcass composition, and meat quality in broilers: A meta-analysis. Poultry Science, 93, 1523-1533.

47. Santos, A.L., Sakomura, N.K., Freittas, E.R., Fortes, C.M.S. and Carrilho, E.N.V.M., 2005. Comparison of free range broiler chicken strains raised in confined or semi-confined systems. Brazilian Journal Poultry Science, 7, 85-92.

48. SAS. 2002-03. SAS/STATE User's Guide: Statistics. Version 9.1. SAS Inst. Inc., Cary, NC.

49. Skomorucha, I., Muchacka, R., Sosnowka-Czajka, E. and Herbut, E., 2008. Effects of rearing with or without outdoor access and stocking density on broiler chicken productivity. Annals of Animal Science, 8, 387-393.

50. Sossidou, E.N., Dal, Bosco, A., Castellini, C. and Grashorn, M.A., 2015. Effects of pasture management on poultry welfare and meat quality in organic poultry production systems. World's Poultry Science Journal, 71, 375-384.

51. Stadig, L.M., Rodenburg, T.B., Reubens, B., Aerts, J., Duquenne, B. and Tuyttens, F.A., 2016. Effects of free-range access on production parameters and meat quality, composition and taste in slowgrowing broiler chickens. Poultry Science, 95, 2971-2978.

52. Tong, H.B., Wang, Q., Lu, J., Zou, J.M., Chang, L.L. and Fu, S.Y., 2014. Effect of free-range days on a local chicken breed: Growth performance, carcass yield, meat quality, and lymphoid organ index. Poultry Science, 93, 1883-1889.

53. Wang, K.H., Shi, S.R., Dou, T.C. and Sun, H.J., 2009. Effect of a free-range raising system on growth performance, carcass yield, and meat quality of slow-growing chicken. Poultry Science, 88, 22192223.

54. Wang, Y., Ru, Y.J., Liu, G.H., Chang, W.H., Zhang, S., Yan, H.J., Zheng, A.J., Lou, R.Y., Liu, Z.Y. and Cai, H.Y. 2015. Effects of different rearing systems on growth performance, nutrients digestibility, digestive organ weight, carcass traits, and energy utilization in male broiler chickens. Livestock Science, 176, 135-140.

55. Ward, J.M., Houston, D.C., Ruxton, G.D., McCafferty, D.J. and Cook, P., 2001. Thermal resistance of chicken (Gallus domesticus) plumage: a comparison between broiler and free-range birds. British Poultry Science, 42, 558-563.

56. Zhang, C., Razafindrabe, R.H., Chen, K., Zhao, X., Yang, L., Wang, L., Chen, X., Jin, S. and Geng, Z., 2018. Effects of different rearing systems on growth performance, carcass traits, meat quality and serum biochemical parameters of Chaohu ducks. Animal Science Journal, 89, 672-678.

57. Zhao, X.L., Siegel, P.B., Liu, Y.P., Wang, Y., Gilbert, E.R., Zhu, Q. and Zhang, L., 2012. Housing system affects broiler characteristics of local Chinese breed reciprocal crosses. Poultry Science, 91, 2405- 
2410.

58. Zhao, X., Ren, W., Siegel, P.B., Li, J., Yin, H., Liu, Y., Wang, Y., Zhang, Y., Honaker, C.F. and Zhu, Q., 2015. Housing systems interacting with sex and genetic line affect broiler growth and carcass traits. Poultry Science, 94, 1711-1717.

\section{Tables}

Table 1 Dietary composition of ration

\begin{tabular}{|ll|}
\hline Ingredient (\%) & Value \\
\hline Corn & 62.11 \\
\hline Soybean meal (48 CP) & 31.05 \\
\hline Soybean oil & 3.01 \\
\hline Sodium chloride & 0.33 \\
\hline Dicalcium phosphate & 1.74 \\
\hline Limestone, pulverized & 1.31 \\
\hline Supplement ${ }^{1}$ & 0.30 \\
\hline DL-Methionine & 0.15 \\
\hline Total & 100.00 \\
\hline Nutrient composition (calculated) & \\
\hline ME, kcal/kg & \\
\hline CP & 20.00 \\
\hline Calcium & 2.81 \\
\hline Phosphorus & 0.93 \\
\hline Lysine & 1.09 \\
\hline Methionine & 0.45 \\
\hline
\end{tabular}

${ }^{1}$ Provided per kg of diet: vitamin $\mathrm{A}, 11,000 \mathrm{IU}$; vitamin $\mathrm{D}_{3}, 2,560 \mathrm{IU}$; vitamin $\mathrm{E}, 44 \mathrm{IU}$; vitamin $\mathrm{K}, 4.2 \mathrm{mg}$; riboflavin, $8.5 \mathrm{mg}$; niacin, $48.5 \mathrm{mg}$; thiamine, $3.5 \mathrm{mg}$; d-pantothenic, $27 \mathrm{mg}$; choline, $150 \mathrm{mg}$; vitamin $\mathrm{B}_{12}$, 33 mg; copper, $8 \mathrm{mg}$; zinc, $75 \mathrm{mg}$; manganese, $55 \mathrm{mg}$; iodine, $0.35 \mathrm{mg}$; selenium, $0.15 \mathrm{mg}$.

Table 2 Growth performance in 4 varieties of Aseel cockerels under different rearing systems (7 to 16 week) 


\begin{tabular}{|c|c|c|c|c|}
\hline \multirow[b]{2}{*}{ Effects $^{2}$} & \multicolumn{3}{|c|}{ Parameters ${ }^{1}$} & \multirow[b]{2}{*}{$M(\%)$} \\
\hline & $\mathrm{BW}(\mathrm{g})$ & WG (g) & $\mathrm{FI}(\mathrm{g})$ & \\
\hline Rearing system ${ }^{3}$ & $(n=72)$ & & & \\
\hline FR & $1371.83 \pm 19.09^{c}$ & $844.96 \pm 18.98^{b}$ & $2.60 \pm 0.04^{b}$ & 4.16 \\
\hline PFR & $1456.00 \pm 17.37^{b}$ & $953.50 \pm 18.54^{\mathrm{a}}$ & $2.93 \pm 0.05^{\mathrm{a}}$ & 0 \\
\hline CF & $1507.29 \pm 23.88^{a}$ & $997.92 \pm 28.75^{a}$ & $3.09 \pm 0.08^{a}$ & 0 \\
\hline Aseel variety 4 & $(n=54)$ & & & \\
\hline $\mathrm{L}$ & $1455.28 \pm 29.62^{b}$ & $933.89 \pm 31.59^{b}$ & $2.80 \pm 0.07$ & 1.85 \\
\hline M & $1437.78 \pm 25.48^{b}$ & $933.61 \pm 29.57^{b}$ & $2.88 \pm 0.09$ & 0 \\
\hline $\mathrm{P}$ & $1374.22 \pm 18.44^{c}$ & $852.83 \pm 23.08^{c}$ & $2.94 \pm 0.08$ & 0 \\
\hline S & $1512.89 \pm 22.87^{a}$ & $1008.17 \pm 24.83^{a}$ & $2.89 \pm 0.09$ & 3.70 \\
\hline Category & $P$-value & & & \\
\hline Rearing system & $<0.001$ & $<0.001$ & $<0.001$ & - \\
\hline Aseel variety & $<0.001$ & 0.001 & $N S^{5}$ & - \\
\hline Rearing system $\times$ Aseel variety 6 & NS & NS & NS & - \\
\hline
\end{tabular}

${ }^{a-c}$ Means within columns with no common superscripts differ significantly $(P<0.05)$.

${ }^{1} \mathrm{BW}=$ body weight; $\mathrm{WG}=$ weight gain; Fl=fold of increase; $M=$ mortality.

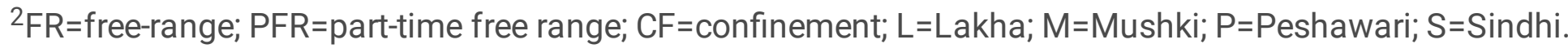

${ }^{3}$ Each value represents the mean of 12 replicates of 6 birds each.

${ }^{4}$ Each value represents the mean of 9 replicates of 6 birds each.

${ }^{5} \mathrm{NS}=$ not significant $(\mathrm{P}>0.05)$.

${ }^{6}$ Interaction of rearing systems and Aseel variety comprised 12 experimental groups $(n=18)$.

Table 3 Slaughter traits in 4 varieties of indigenous Aseel cockerels under different rearing systems (16week) 


\begin{tabular}{|lllll|}
\hline & \multicolumn{2}{l}{ Effects $^{1,2}(\mathrm{n}=24)$} & P-value \\
\cline { 2 - 5 } Parameters $^{3}$ & FR & PFR & CF & \\
\cline { 1 - 4 } CY (\%) & $61.37 \pm 0.25^{\mathrm{c}}$ & $62.62 \pm 0.35^{\mathrm{b}}$ & $65.49 \pm 0.26^{\mathrm{a}}$ & $<0.001$ \\
\hline BR (\%) & $24.81 \pm 0.23^{\mathrm{a}}$ & $22.88 \pm 0.28^{\mathrm{b}}$ & $22.64 \pm 0.22^{\mathrm{b}}$ & $<0.001$ \\
\hline TH (\%) & $16.39 \pm 0.18^{\mathrm{c}}$ & $17.73 \pm 0.17^{\mathrm{b}}$ & $19.18 \pm 0.21^{\mathrm{a}}$ & $<0.001$ \\
\hline DS (\%) & $14.43 \pm 0.20^{\mathrm{b}}$ & $15.06 \pm 0.37^{\mathrm{b}}$ & $17.77 \pm 0.28^{\mathrm{a}}$ & $<0.001$ \\
\hline W (\%) & $11.87 \pm 0.22$ & $12.37 \pm 0.18$ & $12.16 \pm 0.19$ & $\mathrm{NS}{ }^{4}$ \\
\hline L (\%) & $2.13 \pm 0.06^{\mathrm{c}}$ & $2.38 \pm 0.04^{\mathrm{b}}$ & $2.75 \pm 0.08^{\mathrm{a}}$ & $<0.001$ \\
\hline G (\%) & $2.65 \pm 0.05^{\mathrm{c}}$ & $2.88 \pm 0.06^{\mathrm{b}}$ & $3.09 \pm 0.06^{\mathrm{a}}$ & $<0.001$ \\
\hline H (\%) & $0.71 \pm 0.01$ & $0.71 \pm 0.01$ & $0.71 \pm 0.01$ & NS \\
\hline
\end{tabular}

${ }^{a-c}$ Means within rows with no common superscripts differ significantly $(P<0.05)$.

${ }^{1} \mathrm{FR}=$ free range; $\mathrm{PFR}=$ part-time free range; $\mathrm{CF}=$ confinement.

${ }^{2}$ Each value represents the mean of 12 replicates of 2 birds each.

${ }^{3} \mathrm{CY}=$ carcass yield; $\mathrm{BR}=$ breast; $\mathrm{TH}=$ thigh; $\mathrm{DS}=$ drum-stick; $\mathrm{W}=$ wing; $\mathrm{L}=$ liver; $\mathrm{G}=$ gizzard; $\mathrm{H}=$ =heart.

${ }^{4} \mathrm{NS}=$ not significant $(P>0.05)$.

Table 4 Slaughter traits in 4 varieties of indigenous Aseel cockerels (16-week). 


\begin{tabular}{|c|c|c|c|c|c|c|}
\hline \multirow[b]{2}{*}{ Parameters ${ }^{3}$} & \multicolumn{4}{|l|}{ Effects $^{1,2}$} & \multicolumn{2}{|c|}{$P$-value } \\
\hline & L & $M$ & $\mathrm{P}$ & S & $\mathrm{AV}$ & $\mathrm{RS} \times \mathrm{AV}$ \\
\hline CY (\%) & $63.28 \pm 0.47^{a}$ & $63.34 \pm 0.56^{a}$ & $62.15 \pm 0.52^{b}$ & $63.86 \pm 0.53^{a}$ & 0.004 & NS \\
\hline BR (\%) & $23.95 \pm 0.33^{a}$ & $23.45 \pm 0.37^{a, b}$ & $22.71 \pm 0.30^{b}$ & $23.67 \pm 0.39^{a}$ & 0.013 & NS \\
\hline $\mathrm{TH}(\%)$ & $17.92 \pm 0.40^{\mathrm{a}, \mathrm{b}}$ & $17.47 \pm 0.37^{b}$ & $17.35 \pm 0.27^{b}$ & $18.34 \pm 0.31^{a}$ & 0.002 & 0.045 \\
\hline DS (\%) & $15.64 \pm 0.55^{\mathrm{a}, \mathrm{b}}$ & $15.79 \pm 0.45^{a, b}$ & $15.14 \pm 0.51^{b}$ & $16.44 \pm 0.38^{a}$ & 0.027 & 0.004 \\
\hline W (\%) & $12.22 \pm 0.24$ & $12.01 \pm 0.29$ & $11.76 \pm 0.21$ & $12.54 \pm 0.14$ & $N S^{4}$ & NS \\
\hline L (\%) & $2.57 \pm 0.09^{a}$ & $2.30 \pm 0.08^{b}$ & $2.35 \pm 0.09^{b}$ & $2.47 \pm 0.10^{a, b}$ & 0.037 & NS \\
\hline G (\%) & $3.00 \pm 0.08^{a}$ & $2.79 \pm 0.07^{b}$ & $2.73 \pm 0.06^{b}$ & $2.98 \pm 0.08^{a}$ & 0.003 & NS \\
\hline$H(\%)$ & $0.70 \pm 0.01$ & $0.71 \pm 0.01$ & $0.71 \pm 0.01$ & $0.73 \pm 0.01$ & NS & 0.020 \\
\hline
\end{tabular}

${ }^{a-b}$ Means within rows bearing no common superscripts differ significantly $(P<0.05)$.

${ }^{1} \mathrm{~L}=$ Lakha; $M=$ Mushki; $P=$ Peshawari; $S=$ Sindhi.

${ }^{2}$ Each value in table represents the mean of 9 replicates of 2 birds each.

${ }^{3} \mathrm{CY}=$ carcass yield; $\mathrm{BR}=$ breast; $\mathrm{TH}$ =thigh; $\mathrm{DS}=$ drum-stick; $\mathrm{W}=$ wing; $\mathrm{L}=$ liver; $\mathrm{G}=$ =gizzard; $\mathrm{H}=$ =heart.

${ }^{4} \mathrm{NS}=$ not significant $(\mathrm{P}>0.05)$.

\section{Figures}


80

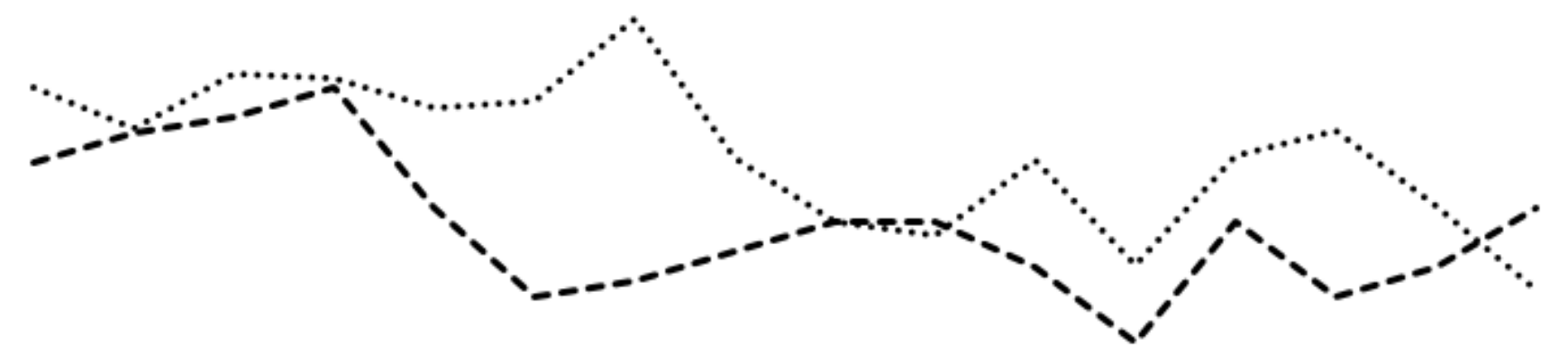

60

50

40

30

\section{..... Avg. Temperature $\left({ }^{\circ} \mathrm{F}\right) \quad$ - - Humidity $(\%)$}

\section{Figure 1}

Variations in temperature $\left({ }^{\circ} \mathrm{F}\right)$ and humidity $(\%)$ by a wet and dry bulb hygrometer (Mason's type, Zeal, England). 